\title{
Doing Innovation in the Wild
}

\author{
Crabtree, A., Chamberlain, A., Davies, M., \\ Glover, K., Reeves, S., Rodden, T. and Tolmie, P. \\ School of Computer Science \\ University of Nottingham, UK \\ \{First name.Last name\}@ nottingham.ac.uk
}

\author{
Matt Jones \\ Department of Computer Science \\ Swansea University \\ Wales \\ mattjonez@gmail.com
}

\begin{abstract}
Doing research in the wild is becoming an increasingly popular approach towards developing innovative computing systems and applications. This paper reflects upon a research project conducted in the wild, and key aspects of the work involved in making the project work, to examine current tropes about the approach. It suggests that doing research in the wild is rather more complicated than is reflected in current understandings, and that even greater involvement of ethnographers, computer scientists, software engineers and other disciplines operating within systems design is needed if innovation is to be effectively driven within and by real world contexts of use.
\end{abstract}

\section{Author Keywords}

Innovation; research in the wild.

\section{ACM Classification Keywords}

H.0. Information Systems; General.

\section{General Terms}

Human Factors.

\section{INTRODUCTION}

In a recent review of the state of the art in HCI, Yvonne Rogers [13] suggests that,

" ... we are witnessing the beginning of a new movement. This time it is 'in the wild' ... Prototyping in the wild is on the rise where objects, artefacts, and other inventions are assembled and then tried out in the settings for which they are envisioned."

Deploying prototypes - trying them out in real settings - is not a new approach in itself, it has been happening for well over a decade and is a key approach to investigating user interactions with potential systems. Deployment orients developers to "what happens on the ground" and enables

\footnotetext{
Permission to make digital or hard copies of all or part of this work for personal or classroom use is granted without fee provided that copies are not made or distributed for profit or commercial advantage and that copies bear this notice and the full citation on the first page. Copyrights for components of this work owned by others than the author(s) must be honored. Abstracting with credit is permitted. To copy otherwise, or republish, to post on servers or to redistribute to lists, requires prior specific permission and/or a fee. Request permissions from Permissions@acm.org.

CHItaly '13, September 16 - 20 2013, Trento, Italy

Copyright is held by the owner/author(s). Publication rights licensed to ACM.

ACM 978-1-4503-2061-0/13/09...\$15.00.

http://dx.doi.org/10.1145/2499149.2499150
}

the drawing out of design principles or recommendations based on users "natural reactions" [2].

The approach has not passed without criticism. Tolmie and Crabtree [14], for example, suggest that deployment is usually something "done to users" rather than "done with them", and so curtails "our ability to determine the actual and potential resonance of research technology" within everyday life. Brown et al. [2] elaborate how deployment may bias understandings of users' natural reactions by introducing "demand characteristics", where users "adjust and report on their behaviour in ways that fit with their perception of investigators' expectations". Kjeldskov et al. [11] demonstrate that the "added value" of deployments over lab-based usability studies "is questionable", showing that little is found through the former that cannot be uncovered via the latter.

There is, of course, a broader cohort of researchers whose studies combine to form a cogent critique of deployment (c.f. the articles cited above for further references), yet the turn to the wild is increasing in popularity rather than decreasing. One of the key drivers of the turn to the wild is a concern not only with deployment but understanding context and the challenges this raises for design, particularly the challenges involved in developing technologies that people can appropriate in real world settings [12]. The turn to the wild might, then, be seen to be as much as turn towards developing innovative systems in context, with users, to enable their uptake and use, as it is about deployment.

Our aim in this paper is to explicate key issues involved in developing a system in the wild that has been appropriated by users. It is not intended as a demonstration of research in the wild however, but rather as a critical examination of the some of the key tropes that have been invoked to characterise the endeavour. These are summed up by Rogers [13] in a review of the state of the art, and they suggest that the turn to the wild dispenses with the need for the formative involvement of ethnographers and computer scientists or software engineers. We present the development of PlaceBooks, ${ }^{1}$ before contrasting its development with existing characterisations of research in the wild. The results suggest that, contrary to current characterisations, research in the wild demands the greater

\footnotetext{
${ }^{1}$ www.placebooks.org
} 
involvement and integration of the various disciplines operating within systems design. That rather than dispense with design disciplines, there is a need to foster closer collaboration between them if innovative solutions are to be developed that can be appropriated in context.

\section{PLACEBOOKS}

PlaceBooks provides an online and mobile solution that enables users to exploit external location-based services and create interactive digital books with rich multi-media content about the places they visit and activities they engage in. External location-based services currently include EveryTrail, OS OpenSpace, and an online archive of historical and geographical resources hosted by the Peoples Collection Wales (PCW). These services are made available through the online editor's media palette (Figure 1), which allows users to import GPX trails, geo-tagged content (including video, audio, and text), and maps, and enable users to situate these resources on a digital canvas. Users can also add content from Dropbox or their hard drives and link this to maps and routes. A basic suite of text tools allows users to weave personal narratives around digital media and create rich interactive accounts of the places they visit and the activities they engage in (e.g., walking, climbing, sight-seeing, etc.).

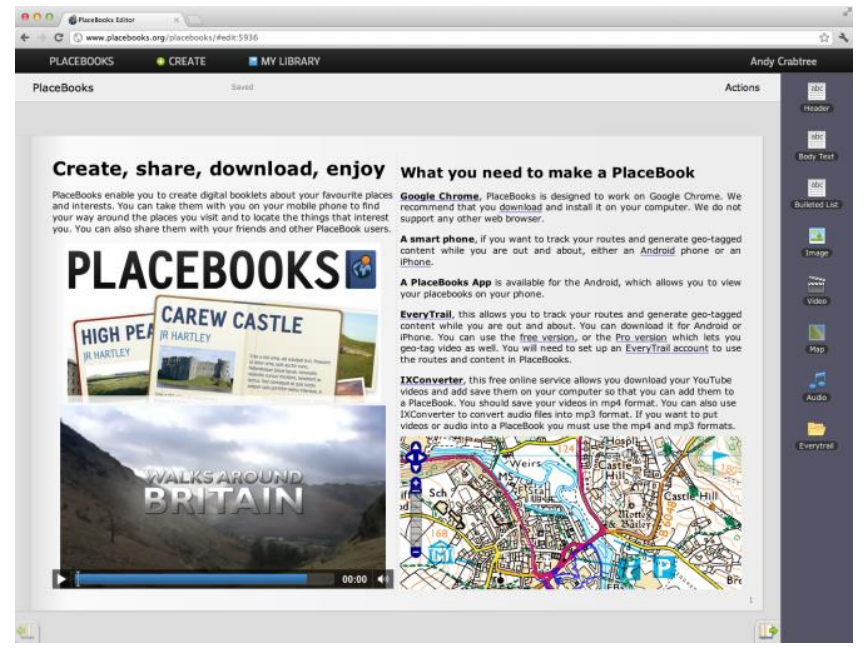

Figure 1. The Online PlaceBooks Editor.

PlaceBooks can be created individually or collaboratively; users can give other PlaceBook users access to individual PlaceBooks and grant them read only or read/write privileges. Finished PlaceBooks can be published to the PlaceBooks server and shared online. Users can search the PlaceBooks server and download and cache PlaceBooks to an Android smartphone (Figure 2). The phone app allows users to download their personal PlaceBooks library to their phone and be able to access them offline. The app also provides features for searching for nearby PlaceBooks, based on your current location and/or activity interests, and exploits the interactional affordances of smartphones in the wild. Thus, together with a phone's GPS and the app's caching techniques, users can track their location in relation to map routes in a PlaceBook and access the rich multimedia content embedded within them.

PlaceBooks is an innovative mash up that glues external services together through a server-side, cloud-based infrastructure. The infrastructure provides the system's media data types (video, audio, maps etc.). It provides database persistence capabilities for storing and retrieving these data types as they are converted from external data sources, authored, retrieved, and so on. It provides the bookshelf and packaging service that translates a user's PlaceBooks collection into a format that the mobile application component can interpret. It provides the account structure, search, and publishing mechanism, which copies a given PlaceBook into a new instance that is accessible to other account holders and non-account holders.
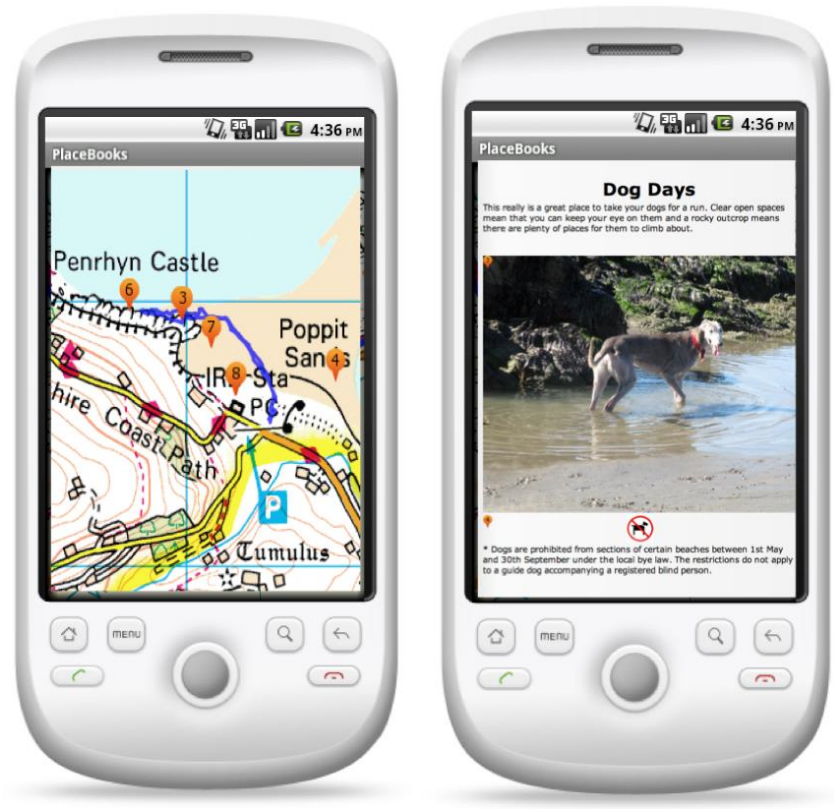

Figure 2. The Mobile PlaceBooks App.

PlaceBooks is also a free-to-use service which, over the course of its development, has been adopted by PCW, an organisation funded by the Welsh Government to support the public in documenting the history and culture of the Welsh landscape. ${ }^{2}$ PCW is currently championing the use of PlaceBooks in a broader European context via its involvement in an INTERREG consortium

\section{DEVELOPING PLACEBOOKS}

The development of PlaceBooks was framed by research interest in location-based solutions to promote engagement with rural places. The system was inspired by Alfred Wainwright's pictorial guides to the Lakeland Fells in the UK, which combine personalised maps, diagrams, and textual accounts of place. While current digital solutions, such as Google Maps, enable the combination of maps and

\footnotetext{
${ }^{2}$ http://placebooks.peoplescollectionwales.com
} 
user-generated content, the ability to create detailed personal and contextually-relevant representations of place is limited. Wainwright's pictorial guides suggested developing a solution that enables users to combine a rich array of digital media including maps, routes, audio-visual media and text.

Just what that solution would look like was anybody's guess at the outset, however. A critical feature of PlaceBooks was situating its development within $a$ community of users to help us work out just what the system could and would look like concretely. The concepts that shaped it were incomplete then - open, flexible, and subject to change, elaborated through ongoing engagement with potential stakeholders. Thus, we decamped from the lab and engaged in a variety of design-oriented activities in the wild, including awareness-raising and networking activities, action research, ethnography, coupled to Agile systems development. Below we consider the nature of these activities and the particular contributions they made to the development of PlaceBooks.

\section{Action Research}

Action Research is an approach that emphasizes "civilly engaged research" as a primary means of "connecting substantial human issues with innovative computing solutions" [9]. It aims to engage salient communities of practice in the definition of problems and iterative development of solutions. From our point of view in undertaking the project the driving question was: which communities of practice would be interested in helping us address the design challenge, where could we go to and who could we ask?

A first point of contact was provided by the Countryside Council of Wales (CCW), a governmental organisation that expressed an early interest in the project and allocated a small amount of staff time to support us, as well as giving us access to one of their fieldsites at Ynyslas. This, while enormously generous and useful was not sufficient in itself. Staff had a particular set of interests that would clearly focus development on their own scientific and educational concerns, and while informative, we were cognisant of the need to widen participation if the project was to be of broader utility. Thus, we adopted five approaches to fostering and broadening civil engagement:

- We exploited a range of media channels to raise awareness of the project, including the BBC, online news, Twitter, Facebook and RSS feeds. Media exposure provided a segue into the local community; the exposure it provided served to pique curiosity, open doors, and seed civil engagement, and online media channels provided an initial point of contact for some.

- We exploited political institutions, including local Members of Parliament and local County and Parish councillors. These were able to direct us towards people and organisations in the local area that they thought the research would be relevant to; again, this opened doors and fostered the construction of a network of participants.

- We carried out an ethnographic reconnaissance of the local area to identify the different communities of practice that made use of the fieldsite. Conducted over two days it identified over one hundred activities occurring at the site and elaborated the scope of the research. It also enabled us to make contact with people and extended the network of participants.

- We contacted local community groups (the local museum, community gardens, rowing club, etc.) to discuss and elaborate initial design ideas and feedback on lo-, mid- and hi-fidelity sketches of potential solutions. This activity also expanded the network of participants; word-of-mouth publicised the project and opened doors to other interested parties in the community.

- Finally we attended workshops and events organised by public organisations involved in heritage, culture, tourism, and enterprise in the rural sector. Initially this enabled us to understand the broader context in which we were working and the interests and concerns of others operating in the field. Over time, as our solution took shape, this provided a forum to disseminate our own work and it is this mechanism that led to our involvement with People's Collection Wales.

The mechanisms of engagement outlined above enabled us to build a network of people, organisations, and institutions having an interest in the project and contributing to it in a variety of ways. Key to the construction of this network was the embedding of a researcher in the local community. In place of user workshops and field trials, we opted to have a researcher work in situ with the local community. This meant that we were able to engage stakeholders on a much more flexible and ad hoc basis than workshops and field trials permit and to create a constant feedback loop between developers and stakeholders.

Having a researcher embedded in situ proved invaluable when we were trying to develop an understanding of the social lie of the land and involve participants in the research. It was through engaging with people in situ, primarily on an individual basis, that we were able to find out who we should and shouldn't engage with, who knew who, what they did, what their interests were, and if they were willing to get involved. In a great many respects the mere act of being on the ground in the community was enough to foster interest and develop connections. Being seen in the community enabled the researcher to be treated as part of the local scene, and this in turn enabled the embedded researcher to assume the role of trusted intermediary facilitating the relationship between development team and the stakeholder network.

\section{Ethnography}

Ethnography is also (but not necessarily) associated with Action Research. It is used to provide "persistent and explicit observation" over extended periods of engagement 
and to enable researchers "to gather data directly in the field as well as from informant accounts" [9]. We did not do extended observation, however. Nor did we exploit the kinds of ethnographic approaches that have arisen within design; e.g., "quick and dirty" and "concurrent" studies [10] devised to ensure that diminishing returns do not set in with the use of ethnography in a design context. In place of long periods of fieldwork traditionally associated with ethnography in anthropology or iterative approaches devised to support systems development, we conducted a short "sensitising study" [3] to help us understand the play of possibilities and develop initial design concepts.

Sensitising studies focus on and elaborate "perspicuous settings" or social settings whose "work" (understood in a broad sense of the word) may shed light on the particular problems our research seeks to address. The notion of perspicuous settings is derived from ethnomethodology [7] and is invoked methodologically as a means of developing empirical insights into the social or collaborative organisation of human activities. Thus,

“... the analyst looks to find, as of the haecceities of some local gang's work affairs, the organisational thing that they are up against ... to learn ... what their affairs consist of as locally produced ... phenomena of order ... “ [7] ${ }^{3}$

The "local gang" in our sensitising study was a family of six: Dave (48) and Chloe (41), who live in a detached house in south-eastern France with their four children, Sarah (6), Marcus (15), Jane (17), and Paul (21). The "work affairs" they were collaboratively busied with, and which furnish us with our perspicuous setting, organising a family day out to a National Park in the French Alps. Through direct observation we learned from the family that the "organisational thing they were up against" looked like this:

- Occasioning the possibility of a day out. Before deciding on a place to visit the first job of work involved in having a family day out was that of 'occasioning a visit'. In addition to making the proposition to have a day out, the work here was concerned to establish whether or not family members actually wanted to have a day out and whether or not this was feasible given their various commitments. Obviously, in this case, the family did want to have a day out and it was feasible. Nonetheless, occasioning a visit was the first job in an unfolding sequence of collaborative work activities.

- Making the possibility concrete. Having agreed to have a day out the next job of work was to figure out where to go. They decided to visit the Chartreuse natural park, though this was an outcome of the family's collaborative work. Arriving at such an outcome involved the iterative making of suggestions based on members individual

\footnotetext{
${ }^{3}$ Haecceities refer to the embodied and material details that make work affairs the unique affairs that they are in any particular setting.
}

interests, the potential novelty and excitement of candidate locations and weighing these alongside a range of practical considerations (time, distance, cost, weather, etc.) The making of suggestions also relied on the use of online resources, including searching for candidate locations, discussing activities indexed by location websites, reading wiki pages for further details, and viewing location maps.

- Making ready for the visit. Once a particular place had been decided on, the work turned towards planning the visit. This involved determining what things family members needed to take with them, when they were going to leave, how they are going to get there, what route to follow and what they are going to do once they are there (which again occasioned the use of online resources), how much money they would need to do the things they wanted to do, who they needed tell about their day out, who would cover contingencies (like feeding the cats), and who in the family should do what and when so that they could all get out of the door on time. Things of relevance to the visit (clothes, maps, food, equipment, etc.) had to be brought together at timely moments. This cannot necessarily be done days ahead but often has to be done just before departure. Thus, food had to be prepared, bags packed, the house be prepared for absence, the car loaded with people and stuff before the door could be locked and the family could get underway.

- Making your way there. In addition to way-finding this involved in-journey entertainments, handling squabbles between the kids, searching out remarkable sights and scenes of interest as the family passed through the landscape around them, and then there were pit stops for fuel, toilets and snacks. A host of things also had to be done when they arrived at their destination: finding a place to park, for example, figuring out what to take with them and what to leave behind, figure out who should take what, and figuring out just where to go from here.

- Making the visit happen. Again, this involved a body of work. The family had to figure out where to go from 'here' (i.e., where they had parked the car). Figuring out where to go next, and getting there, relied on the family 'reading' the landscape around them and drawing in particular on situated displays which 'pointed' them in the right direction and in other ways 'pointed out' relevant features of the landscape (paths, sites of interest, cafes, toilets, etc.). As the family went about the business of visiting it sought out and followed signs and paths, used guides and maps, engaged in pleasurable activities (sightseeing, snowball fights, eating), and took photos as they went about having their day out.

- Calling it a day and heading home. The visit was brought to a close by the demand for dinner. The family returned to the car park and made its way home. The work of returning home was much like leaving. The car had to be loaded, way-finding had to be done, the journey had to be filled. Now, however, the family members had other things to occupy themselves with: the things they saw, 
the things they did, what was good, and what wasn't, what they should do again, and when. Visits beget visits and discussing the next adventure turned out to be just as good a way to fill the journey home as was dissecting the one they just had.

- Getting home. When the family arrived home the house was unlocked, the car unloaded, stuff (coats, our boots, rubbish from the journey home, etc.) put away or put somewhere on hold until later. The kids went for their baths, the parents checked on the pets, and checked to see if any messages had been left, etc. The household routine resumed. The visit rapidly receded into the past, it was done, dusted, a grand day out of little relevance to anyone else but them. When asked they said it might be newsworthy to a select few. Grandma and Granddad might enjoy hearing what the kids did over the weekend, friends of a good place to take their kids some day too. What of their own remembrance of the event? What of those photos they took? "We're in no rush, they're on the camera; we'll sort them out when we have time."

Obviously we have glossed over a great deal of the actual work of visiting [c.f. 15 for further details] and it might be thought that not much can be gleaned for the design of a generic solution from a single study of a single family's day out anyway. However, if we look at the work of visiting place from an intersubjective point of view [1] we can see that the work the family engages in is shot through with familiar events that we also recognise as ordinary members of society.

The sequence of collaborative activities elaborates the organisational things that families (and other small groups) everywhere are up against when they want to visit a place for the purposes of having a day out together. Regardless of their access to technology, the sequence of collaborative work reveals the organisational things they must address, from the irremediable need to occasion the day out through to deciding where to go, planning the visit, preparing for it, going there, arriving, and so on.

The organisational things revealed by consulting a perspicuous setting reveal how having a day out is locally ordered by family members as a social enterprise. Thus, the local order is a social order and it is because it is social that we recognise it in our capacity as ordinary members too and the study of one family's day out enables us to generalise to the orderly ways in which this activity or ensemble of activities is assembled and accomplished [4]. Furthermore, identification of this familiar, recognisable order elaborated the play of possibilities for design and provided a resource for us to draw on and shape our initial design ideas.

\section{Doing innovation in the wild}

The ethnographic study sensitized the design team to the kinds of activity it could be designing support for: deciding where to go, planning the visit, arriving and doing the visit, and sharing post-visit experiences in particular. That these aspects of the work already draw upon location-based resources, digital and physical, suggested them as strong candidates for support, and extended the focus of design from the act of visiting itself to what occurs before and afterwards as well. The study did not "tell us what to build", however, but instead elaborated the scope of design and areas in which we might intervene.

Working out what to build drew on other resources too, including the notion of mobile "location books" articulated by interaction designers in the team and digital leaflets inspired by a small box of beautifully designed tourist information sheets mixing maps, routes, texts and narratives together, which were brought to a design workshop by the Interpretations Officer at CCW. In the mix of ethnographic results, the design idea of mobile location books, and existing tourist leaflets, a design concept began to emerge that would enable people to assemble an array of digital media into digital leaflets of their own before they visited a place, which could be printed off or cached on mobile devices and accessed during visits, and be edited after a visit before being published online and shared with others.

In short, the concept of PlaceBooks began to emerge. Scenarios and mock ups were created, the latter being shown to the broader community of participants initially by way of a sanity check. This also served to raise specific requirements: editing other people's PlaceBooks, searching for published PlaceBooks via mobile devices when visiting places, collaboratively producing PlaceBooks, making books of indeterminate length rather than leaflets, and so on. Requirements emerged in piecemeal fashion as the development of PlaceBooks progressed and the design concept became more and more concrete.

Development was conducted using Agile methods, with the embedded community researcher acting in the role of 'product owner' to ensure that development met stakeholder need. The embedded researcher was not a systems developer but played a full and active role in 'sprint' planning meetings, feeding back latest issues to emerge from testing in the field and shaping the prioritisation of development tasks. This approach was marked by an iterative series of 'time-boxed sprints', underpinned by the continuous interdisciplinary process of reflection, elaboration and modification driving community engagement.

This process of innovation in the wild was also marked by project wide reviews involving all members of the design team, including PCW who became the key user group, held at regular quarterly periods over 18 months of development. These brought action researchers, ethnographers, HCI researchers, and other stakeholders together to assess progress. Importantly, these reviews took place in context. Thus, instead of conducting them in a well-connected lab, they were held in settings where the technology was intended to be used (remote rural settings) and its use studied by ethnographers and reflected on in situ by the whole team. 
These reviews surfaced a broad range of issues with the underlying technology - poor and non-existent connectivity, flaky APIs, limited route mapping, slow and disruptive uploading of resources, etc. - all of which elaborated new requirements and drove development on. Situating the development team in rural locations, driving around hill roads, visiting local settings and scenes, writing code in hotel meeting rooms, etc., all served to emphasize that the focus of the work was not to produce experimental prototypes. Creating designs and implementations in situ was both inspiring, helping the team see the potential usefulness of the system being created, and humbling, a reminder of the richness of the mundane ecology it would have to accommodate.

\section{DICUSSION}

Our experience of doing innovation in the wild suggests that there is need to revise current understandings of the turn to the wild itself and what it entails. A number of tropes regarding research in the wild have been summed up by Rogers [13]. They provide several characterisations that are not reflected in our own experience of developing PlaceBooks. We review each in turn.

\section{It is Not Necessary to Identify User Need}

Rogers' review of research in the wild suggests that it is an approach which, although concerned with designing technologies for everyday life, may nevertheless dispense with the standard design preoccupation of understanding user needs.

"Novel technologies are developed to augment people, places, and settings, without necessarily designing them for specific user needs. [Instead] objects, artefacts, and other inventions are assembled and then tried out in the settings for which they are envisioned. " [13]

The longstanding concern with user needs is replaced with a preoccupation to understand how people react to novel design interventions and how they might integrate them into everyday life.

We understand the motivation. PlaceBooks was not, at the outset, designed with a clear set of user needs in mind. First there was a problem-space as it were, then a loose collection of ideas and concepts, then there were interested user communities, followed by a key user group. However, as the design of PlaceBooks took shape and users became more interested in its potential, then so too users' needs began to emerge: they wanted to do particular kinds of things with it, they wanted it to offer particular services and support. We are not criticising the pursuit of novelty for novelty's sake then when we question the necessity of identifying user need, nor are we insisting that design must have a clear understanding of what those needs are at the outset. Rather, we are suggesting that design inevitably runs up against user needs, particularly as designs take shape and users express interest in appropriating them.
Observation of Existing Practice is Not Necessary

A key characterisation of research in the wild is that it is not and does not need to be predicated on observation of existing practice.

"Designing in the wild differs from previous ethnographic approaches to interaction design by focusing on creating and evaluating new technologies in situ, rather than observing existing practices and then suggesting general design implications or system requirements." [13]

While we would not insist on ethnography being a part of any research project, in the wild or elsewhere, observations of existing practice did play a formative role in the design of PlaceBooks. Indeed, the system would not be what it is were an ethnographic reconnaissance of salient rural activities and sensitising study of visiting not conducted, or if ethnographers did not play a formative role in project reviews. This is not to say that every design intervention in the wild should, therefore, involve ethnographic study. It is to suggest that observations of practice may add value by sensitising designers to the order of the experience they could be designing for. This is what we can learn from studies of existing practice.

The characterisation of ethnography in the turn to the wild is also questionable. What is at issue here is the characterisation of ethnography as something concerned with implications for design or requirements. Our experience suggests that observational studies can play a much more creative role in design than this view credits them with, sensitising designers to the collaborative work implicated in the production of social order and elaborating concrete possibilities for design to explore. We would question too the implicit and untouched question as to the duration of ethnographic studies. These are traditionally seen as taking some time, even in design settings. The development of PlaceBooks suggests that even short studies may yield useful results for design [4].

\section{Computer Scientists and Engineers are Not Necessary}

This, perhaps, is the most contentious of tropes: the view that computer scientists or software engineers are not needed to conduct research in the wild.

“... made possible by the arrival of a cornucopia of affordable 'plug and play' technologies ... ... .... Armies of computer scientists and engineers are no longer needed. Interaction designers, with less technical expertise and modest resources, can conjure, create, and deploy a diversity of prototypes in all manner of places in the everyday world." [13]

While the possibilities afforded to interaction designers by plug and play technologies are important, our experience suggests that the involvement of computer scientists and engineers is critical if innovative systems are to be developed and appropriated by users. 
PlaceBooks is to some large extent a mash up of existing services but this does not mean it was easy to construct. Existing services needed to be glued together and underlying infrastructure needed to be constructed to provide that glue. Without the infrastructure there would have been no possibility of users appropriating PlaceBooks. Construction of the infrastructure required computer science expertise and engineering acumen. Their close integration with other competences in the team (e.g., interaction design) resulted in the piecemeal construction of a system that demonstrably responded to user need and worked to sustain community engagement and participation. Our experience suggests that doing research in the wild requires serious engineering capability if users are to remain engaged in the research and the technology being developed is ultimately to be appropriated by them.

\section{Evaluating Prototypes in situ is Essential}

Particular emphasis is currently placed on evaluating prototypes in the wild. Deployment is seen to be key.

"A central part of designing in the wild is evaluating prototypes in situ ... whereas the burning question in HCI was once 'How many participants do I need?' the hotly debated question is now 'How long should my study run for? ', [13]

Our experience suggests that the emphasis on evaluation is massively overstated. We can see why the emphasis exists if deployment is the only contact that users have with the technology. However, it is this kind of limited contact that the development of PlaceBooks draws into question. The efficacy of the project depended on sustained engagement, not a limited period of contact with users.

Consequently, evaluation collapsed into a continuous process of reflection, modification and elaboration driven by the embedded community researcher to shape the ongoing development of a useful system [8]. We would suggest that the emphasis on evaluation as a key part of the development process in the wild be replaced with an emphasis on fostering and maintaining sustained engagement throughout that process. This means that users should not only be involved in evaluation but in design activities as well, both critiquing designs and elaborating alternatives. Our experience suggests that this broader involvement is central to developing innovative systems that users want to appropriate.

\section{REVISING MODELS OF RESEARCH IN THE WILD}

Our reflections on doing research in the wild should not be understood as a critique of Yvonne Rogers' work. We view it is exemplary and no more or less that an accurate reflection of what is happening in the broader community, and it is to the broader community that our reflections on doing innovation in the wild are addressed.

\section{The Existing Model}

Were the turn to the wild only intended to be a turn that enables interaction designers to explore the interactional affordances of new technology, then the model outlined by Rogers may be sufficient. But if the turn to the wild is of broader moment, something that may have a radical effect on the construction of innovative systems, then there is a strong sense in which the existing model is inadequate. The repeated invocation and use of such terms as "designing technologies", "creating technologies", "developing technologies", and so on, suggests that the turn to the wild is indeed supposed to be of broader moment and relevance: something that reshapes design practice. Indeed, "a move into a new research paradigm".

However, current tropes reduce the wild to little more than a vehicle for evaluating proof of concept prototypes. The turn to the wild would, then, seem to be of little moment on this reading. Its value over lab studies, as Kjeldskov et al. [11] demonstrate, questionable. As Davies [5] puts it,

"The problem, very often, is that there is no actual concept to be proven. Either the concept has already been proven viable ... is never in any doubt ... or is not actually proved by the demonstrator (proof is a very strong term!). This is why Kjeldskov's arguments have some validity - in many cases laboratory based tests will do just as good a job of evaluating a concept as a ... field trial."

Thus, the existing model reduces the wild to a site where field trials take place, leaving the problems that accompany such endeavours operative and unresolved [c.f. 2, 11, 14].

\section{Revising the Model}

If, on the other hand, the turn to the wild is a turn towards a new way of doing innovation in order to ensure that systems can be appropriated by users, then the move is, potentially, very significant. However, the tropes that are currently invoked to characterise research in the wild stand in need of major revision, at least they do if appropriation is to have any serious meaning. Our experience suggests that appropriation turns upon the construction of robust solutions. That is, solutions that work, that deliver the services users need, that do not continuously break down and require constant bootstrapping to make them work. Our experience also suggests that the development of robust solutions requires greater integration of disciplines operating within design, not less.

Research in the wild requires the bringing together of design disciplines and users to develop solutions that can be appropriated. However, the central tropes of the existing model do not reflect the interdisciplinary work involved in developing robust systems in the wild and the importance of developing solutions with respect for user need and orderliness of current practice. The model stands in need of amendment and we would also suggest that, as part of this, the emphasis on evaluation be replaced with an emphasis on a continuous community-oriented process of reflection, elaboration and modification shaping the co-realisation of innovative systems. 


\section{Deployment versus appropriation}

The core point of tension revolves around the emphasis placed on deployment and the rationale underpinning the turn to the wild, which suggests that the approach is a better and more valid way of developing technologies that can be appropriated by users. Deployment is currently treated as the key means of bringing appropriation about, creating that moment when users are confronted by new possibilities and designers get to learn how new technologies are received and treated in real contexts of use along with the challenges this raises for appropriation. As Fox et al. [6] put it,

“ ... deployment lets you observe people using the system as part of their daily lives, making it an important step toward the long-term goal of developing widely adopted ... technology. Only through deployment can we learn about unexpected problems that might be critical in real systems."

There is, however, an inherent tension between the motivation towards deployment and the reality of it, namely the typically short duration of deployment and the longterm goal of developing widely adopted technology or technology that is appropriated by users. While the burning question in contemporary times may well be "how long should my study run for?", the answer (for a host of practical reasons) is usually a few weeks or months at most.

This is not to say that there is no value in doing deployments. As Davies [5] puts it,

“ ... the target deployment environment often has very little in common with the laboratory environment in which the system was developed. As a result systems often require substantial redesign once they are deployed. For example, assumptions about network availability and quality, user behaviour or application utility are often shown to be flawed once the system is out 'in the wild' ... it is impossible to understand ahead of time the impact of the environment on technology (or indeed, the impact of technology on the environment) and this is often critical to system design."

Deployment is an extremely valuable aid to understanding the real world challenges that confront the uptake and use of novel systems, but it is not a solution to the problem of appropriation. More is required.

\section{CONCLUSION}

We have reflected on the development of a system in the wild that suggests that the development and appropriation of innovative solutions turns upon the close coupling of multiple design disciplines and sustained user engagement in the construction of robust solutions. This sits uncomfortably with current characterisations of the turn to the wild, which suggest there is less need for interdisciplinary work, computer science expertise and software engineering acumen.
Our experience of developing PlaceBooks suggests that there is a need for the existing model of research in the wild to be revised. Of particular note is the need for the emphasis on deployment and evaluation to be reappraised. While deployment is an important activity, shedding light on real world challenges of appropriation in context, it does not stand alone. Rather deployment needs to be reconfigured as part of a broader collaborative process which embeds researchers in relevant user communities and leverages understandings of user needs and the orderliness of current practice into the construction of robust solutions that ongoingly engage users in design and drive appropriation.

\section{ACKNOWLEDGMENTS}

The research on which this article is based was funded RCUK research grants EP/I001816/1, EP/I001778/1, EP/G065802/1, EP/J000604/1 and EP/J000604/2.

\section{REFERENCES}

1. Berger P. and Luckmann T. (1966) The Social Construction of Reality, Anchor Books.

2. Brown B., Reeves S. and Sherwood S. (2011) "Into the wild”, Proc. of CHI, pp. 1157-1666, Vancouver, ACM.

3. Crabtree A., Rouncefield M. and Tolmie P. (2012) Doing Design Ethnography, Springer.

4. Crabtree A., Tolmie P. and Rouncefield M. (2013) "How many bloody examples do you want?", Proc. of ECSCW, September 21-25, Paphos, Cyprus, Springer.

5. Davies, N. (2005) "Proof-of-concept demonstrators and other evils of application-led research", Proc. of PerCom, Workshop 1, Munich, IEEE.

6. Fox A., Davies N., de Lara E., Spasojevic M. and Griswold W. (2006) "Real-world ubicomp deployments”, IEEE Pervasive Computing, vol. 5 (3), pp. 21-23.

7. Garfinkel H. and Wieder D.L. (1992) "Two incommensurable, asymmetrically alternate technologies of social analysis", Text in Context: Contributions to Ethnomethodology (eds. Watson G. and Seiler S.M.), pp. 175-206, Sage.

8. Greenberg S. and Buxton B. (2008) "Usability considered harmful (some of the time)", Proc. of CHI, pp. 111-120, Florence, ACM.

9. Hayes G. (2011) "The relationship of action research to human computer interaction", ACM ToCHI, vol. 18 (3), Article 15.

10. Hughes J., King V., Rodden T. and Andersen H. (1994) "Moving out of the control room", Proc. of CSCW, pp, 429-438, Chapel Hill, ACM.

11. Kjeldskov J., Skov M., Als B. and Høegh, R. (2004) "Is it worth the hassle?", Proc. of MobileHCI, pp. 61-73, Glasgow, Springer.

12. Rogers Y., Connelly K., Tedesco L., Hazlewood W., Kurtz A., Hall R., Hursey J. and Toscos T. (2007) "Why it's worth the hassle", Proc. of UbiComp, pp. 336-353, Innsbruck, Springer. 
13. Rogers Y. (2011) “Interaction design gone wild”, $A C M$ Interactions, vol. 18 (4), pp. 58-62.

14. Tolmie P. and Crabtree A. (2008) "Deploying research technology in the home", Proc. of CSCW, pp. 639-648, San Diego, ACM.
15. Tolmie P. and Crabtree A. (2013) "A day out in the country", Ethnomethodology at Play (eds. Tolmie P. and Rouncefield M.), pp. 21-52, Ashgate 